This is the accepted version of the article:

Luis-Barrerra J ., Cano R., Imani-Shakibaei G., Heras-Domingo J., Pérez-Carvajal J., Imaz I., Maspoch D., Solans-Monfort X., Alemán J., Mas-Ballesté R.. Switching acidic and basic catalysis through supramolecular functionalization in a porous 3D covalent imine-based material. Catalysis Science and Technology, (2019). 9. : 6007 - . 10.1039/c9cy01527b.

Available at: https://dx.doi.org/10.1039/c9cy01527b 


\title{
Switching acidic and basic catalysis through supramolecular functionalization in a porous 3D covalent imine-based material
}

\begin{abstract}
Javier Luis-Barrerra, a Rafael Cano, b Ghazaleh Imani-Shakibaei, a Javier Heras-Domingo, c Javier Pérez-Carvajal, d Inhar Imaz, d Daniel Maspoch, d,e Xavier Solans-Monfort, * c José Alemán*a,f and Rubén Mas-Ballesté *b,f

Non-covalent inclusion of small acid and base molecules $\left(\mathrm{CH}_{3} \mathrm{COOH}\right.$ and $\left.\mathrm{NEt}_{3}\right)$ in an imine structure based on micrometre COF-300 crystals and amorphous nanoparticles results on the facile modulation of its acid-base properties. Such strategy results in the triggering of acidic/basic catalytic activity of the otherwise inactive materials towards ring-opening epoxide and Knoevenagel condensation reactions. For both reactions, amorphous nanoparticles are better catalysts than micrometre crystals as they exhibit a higher external surface area. The found activities and stability of this supramolecular functionalization are modulated by confinement effects, which are rationalized with the help of DFT theoretical calculations. All results obtained suggests that reaction catalysed by these functionalized materials occur confined at pores closer to the material surface, which makes possible size-discrimination phenomena, and explains the major activity of the nanoparticulated material.
\end{abstract}

\section{Introduction}

The development of molecules and materials with catalytic cavities, inspired on biological systems, such as enzymes, has been a main topic in modern chemistry. For instance, different molecules known as molecular flasks ${ }^{1}$ are able to catalyse a variety of reactions in confined spaces. The outstanding performance of such molecular systems and other porous materials lays not only on the design of active catalytic centres, but also on the easy tuning of environment in a confined space, resulting on different regio- ${ }^{2}$ chemo- ${ }^{3}$ and stereo-selectivities ${ }^{4}$ in different reactions. In addition, the proximity between the different reactants in the confined space can result in an enhancement of the catalytic activity. ${ }^{5}$ Furthermore, confined catalysis offers the possibility to perform size-selective reactions, especially important when working with mixtures of compounds with similar chemical and physical properties. During the last years, confinement effects have been particularly studied in different porous materials such as

\footnotetext{
a. Department of Organic Chemistry (module 01), Facultad de Ciencias, Universidad Autónoma de Madrid, 28049 Madrid, Spain. E-mail: jose.aleman@uam.es; www.uam.es/iose.aleman

b. Department of Inorganic Chemistry (module 07), Facultad de Ciencias, Universidad Autónoma de Madrid, 28049 Madrid, Spain. E-mail: ruben.mas@uam.es

c. Department of Chemistry, Facultat de Ciències, Universitat Autònoma de Barcelona, 08191 - Bellaterra, Spain. E-mail: xavier.solans@uab.cat

d. Catalan Institute of Nanoscience and Nanotechnology (ICN2), CSIC and BIST,

08191 - Bellaterra, Spain. E-mail: daniel.maspoch@icn2.cat

e. ICREA, Pg. Lluís Companys 23, Barcelona, 08010, Spain.

f. Institute for Advanced Research in Chemical Sciences (IAdChem), Universidad

Autónoma de Madrid, 28049 Madrid, Spain.

+ Footnotes relating to the title and/or authors should appear here.

Electronic Supplementary Information (ESI) available: [details of any supplementary

information available should be included here]. See DOI: 10.1039/x0xx00000x
}

zeolites,$^{6}$ mesoporous silica ${ }^{7}$ and metal-organic frameworks (MOFs). ${ }^{8}$

In 2005, Yaghi and co-workers described a new concept on the reticular chemistry field: the covalent-organic frameworks (COFs). ${ }^{9}$ Their use as heterogeneous catalysts offers advantages compared to MOFs such as increased activity, durability and recyclability. COFs are based on the covalent linkage of organic subunits into two- or three-dimensional porous crystalline structures. Therefore, they show predictable composition, topology and porosity. As a consequence, COFs have been explored for applications related to gas storage and separation, ${ }^{10}$ ultrasensitive sensing, ${ }^{11}$ electronic applications, ${ }^{12}$ and clean energy technologies. ${ }^{13}$ However, only few recent studies initiated the exploration of their catalytic applications. ${ }^{14}$ In 2014, Yan et al. described the intrinsic basic property of a three-dimensional (3D) imine-based COF useful for the catalytic Knoevenagel reaction. ${ }^{15}$ After this achievement, other groups have employed two main covalent strategies in order to tune the catalytic activity of different COFs. The first one consisted in the post-functionalization of the material, attaching organic pending arms (top-left, Scheme 1$)^{16}$ or metal nano-particles, ${ }^{14}$ which are both $s$ irreversible functionalization processes. A second strategy relayed in the use of catalytic backbones, which often requires complex synthetic modifications of building blocks (top-right, Scheme 


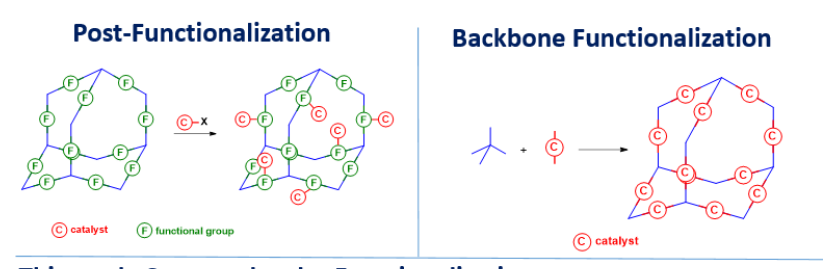

This work: Supramolecular Functionalization

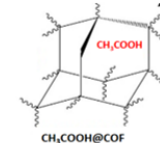

ON
Acid catalysis

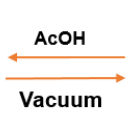

Vacuum (1)

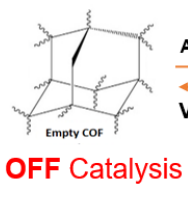

$\frac{\mathrm{AcOH} / \mathrm{Et}_{3} \mathrm{~N}}{\stackrel{\text { Vacuum }}{\longleftarrow}}$

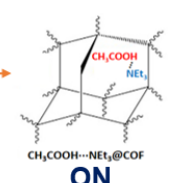

Basic catalysis
Scheme 1 Previous strategies for the catalytic functionalization materials and the supramolecular used in this work.

1). ${ }^{17}$ Although these are interesting approaches, they require predetermined specific architectures or, in some cases, complicated post-functionalization processes.

As an alternative to these strategies shown above, supramolecular functionalization appears as an easy way to modulate and direct several properties of COFs. In particular, hydrogen bonding interactions between COFs and small, molecules have been recently demonstrated and applied to drug delivery and molecular recognition systems. ${ }^{18}$ In addition several porous materials with pre-designed structures that could make possible proton conduction mechanism have been applied to proton-exchange in fuel membranes. ${ }^{19}$ However, to the best of our knowledge, such supramolecular functionalization strategy, to obtain catalytic COF-molecule confined systems, have never been applied to catalyse chemical organic transformations.

Herein we show that this latter strategy can be applied to functionalize COF-related materials for catalytic applications (bottom, Scheme 1). These materials can be reversibly functionalized through supramolecular interactions with two simple model molecules: a carboxylic acid (acetic acid) that has been used to catalyse ring-opening reactions of epoxides; and a Brønsted base (triethylamine) that has been used to catalyse Knoevenagel condensation.

\section{Results and discussion}

Preparation and characterization of a-3, c-3 and derivatized materials.

We have demonstrated that these porous materials can be reversibly functionalized (Figure 1) through supramolecular interactions. We selected the 3D COF-300 ${ }^{20}$ made of terepthalaldehyde (1) and tetra-(4-anilyl)-methane (2) as it is stable up to $490{ }^{\circ} \mathrm{C}$, in water and common organic solvents. COF-300 was synthesized by a well-known two-step process:21,22 first, amorphous imine polymer nanoparticles (hereafter called amorphous-3 or a-3) were formed; and subsequently, these a-3 nanoparticles were further reacted to form micrometre COF-300 crystals (hereafter called crystalline3 or c-3). In a first step, a room temperature synthesis in the

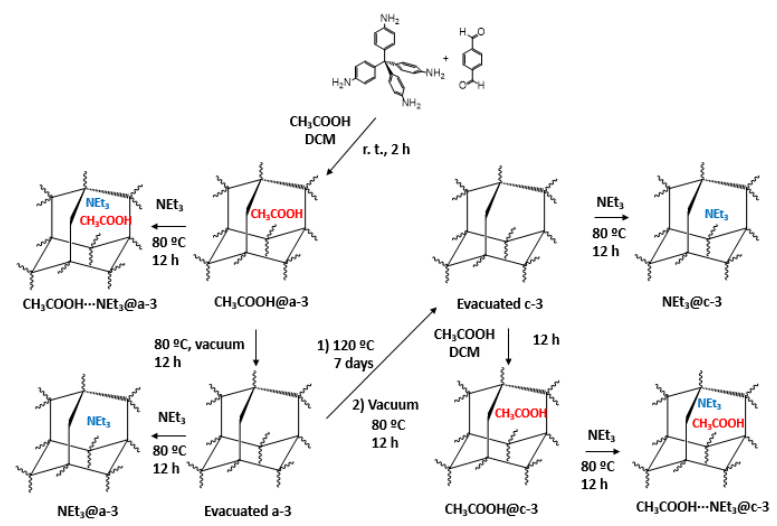

Figure 1. Schematic representation of the preparation of a-3, c-3 and related supramolecular materials.

presence of acetic acid allowed the formation of the amorphous imine-based polymer nanoparticles a-3, which contains $\mathrm{CH}_{3} \mathrm{COOH}$ molecules inside its structure. ${ }^{23}$ Then, in a second step, these nanoparticles were subjected to a dynamic covalent chemistry to crystallize them under similar conditions to those reported by Dichtel et al. ${ }^{22}$

SEM images of the solid collected in the first step revealed the formation of amorphous-nanoparticles with diameters of nearly $100 \mathrm{~nm}$ (Figure 2; see S. I., Figures S1-3 for powder X-ray diffraction (PXRD) data). Solid-state MAS- ${ }^{13} \mathrm{C}-\mathrm{NMR}$ and FT-IR spectra confirmed the chemical identity of the material (see $S$. I., Figures S6 and S9-12, respectively). The FT-IR spectrum of COF-300 showed the $\mathrm{C}=\mathrm{N}$ stretching modes characteristic for imines at 1620 and $1202 \mathrm{~cm}^{-1}$. The solid-state MAS- ${ }^{13} \mathrm{C}-\mathrm{NMR}$ spectrum was also in agreement with the formation of the imine bonds. Thermogravimetric analysis (TGA) data revealed a $2.6 \%$ of volatile molecules lost in the range of 50-400 $\mathrm{C}$, which was consistent with the presence of acetic acid even after numerous washing procedures with distinct solvents (see S. I., Figure S14). The presence of acetic acid was further confirmed by mass spectrometry coupled to TGA analysis, which showed peaks at $\mathrm{m} / \mathrm{z}=15$ and 43 that can be assigned to $\left[\mathrm{CH}_{3}\right]^{+}$and $\left[\mathrm{CH}_{3} \mathrm{CO}\right]^{+}$, respectively. Further evidence of the presence of acetic acid molecules inside $\mathbf{a}-\mathbf{3}$ was acquired by solid-state MAS- ${ }^{13} \mathrm{C}-\mathrm{NMR}$. To this end, a-3 was synthesized in the presence of ${ }^{13} \mathrm{C}$ isotopically labelled acetic acid. Solid-state MAS- ${ }^{13} \mathrm{C}-\mathrm{NMR}$ of this newly synthesized a-3 gave a clear evidence of the presence of ${ }^{13} \mathrm{C}$-enriched acetic acid molecules by means of the $\mathrm{CH}_{3}$ signal at 20 ppm (see S.I., Figure S8). Altogether, these observations confirmed the formation of $\mathrm{CH}_{3} \mathrm{COOH} @ a-3 .{ }^{24}$

The evacuation of all $\mathrm{CH}_{3} \mathrm{COOH}$ molecules in $\mathrm{CH}_{3} \mathrm{COOH} @ a-$ 3 was achieved by heating it at 80 을 during 12 hours under vacuum $(1 \mathrm{mmHg})$. The resulting material showed the same morphology than its precursor (see S. I., Figure S5). First evidence of the evacuation of all acetic acid molecules was obtained by TGA analysis, from which no significant weight loss in the range of 50-400 $\cong$ C was observed (see S. I., Figure S15). We also demonstrated the removal of acetic acid 


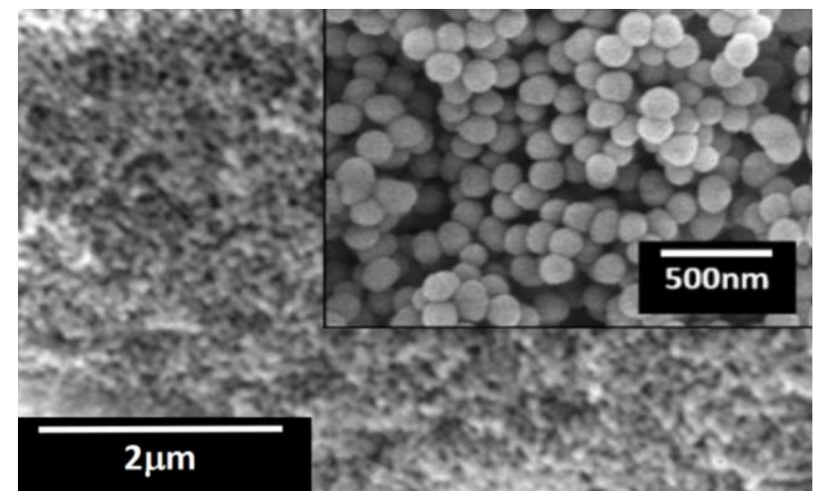

Figure 2 Representative SEM images of $\mathrm{CH}_{3} \mathrm{COOH} @ a-3$.

molecules by performing solid-state MAS- ${ }^{13} \mathrm{C}-\mathrm{NMR}$ of a sample of ${ }^{13} \mathrm{C}$ enriched $\mathrm{CH}_{3} \mathrm{COOH} @ a-3$ exposed to identical activation conditions (see S. I., Figure S8).

In our quest of switching from acidic to basic properties of the material, a sample of $\mathrm{CH}_{3} \mathrm{COOH} @ a-3$ was treated with pure triethylamine (1 mL per $10 \mathrm{mg}$ of $\mathbf{C H}_{3} \mathbf{C O O H @ a - 3 ) ~ o v e r n i g h t ~ a t ~}$ 80 ㅇ․ Again, SEM images confirmed the retention of the size and morphology of the nanoparticles after both amine treatments (see S. I., Figure S5). TGA analysis of $\mathrm{CH}_{3} \mathrm{COOH}$...NEt ${ }_{3} @ a-3$ showed a larger weight loss from 50 으 to 400 ㅇ $\mathrm{C}$ in comparison to $\mathrm{CH}_{3} \mathrm{COOH} @ a-3$ (4.6 \% versus $2.6 \%$ ). Here, at this temperature range, mass spectrometry coupled to TGA revealed peaks at $\mathrm{m} / \mathrm{z}=43$ and 51 in the ionization cell, which were assigned to $\left[\mathrm{CH}_{3} \mathrm{CO}\right]^{+}$and $\left[\mathrm{HNEt}_{3}\right]^{2+}$, respectively, thereby confirming the presence of both acetic acid and triethylamine molecules (see S. I., Figure S17). The supramolecular interaction is strong enough to prevent leaching after 14 hours of stirring the material in toluene. Such stability is suggested by the fact that after such treatment no evidences of acetic acid nor $\mathrm{NEt}_{3}$ were detected NMR measurements.

In order to determine the reversibility of the functionalization of this material, we performed vacuum in a sample of $\mathrm{CH}_{3} \mathrm{COOH}$... NEt ${ }_{3} @ a-3$, recovering the evacuated a-3, as revealed by TGA. It is worth mentioning that direct reaction of evacuated a-3 with pure $\mathrm{Et}_{3} \mathrm{~N}$ results on a functionalized material in which the interactions between the imine structure and the guest molecules are very weak. Therefore, such functionalized material resulted in massive leaching of $\mathrm{Et}_{3} \mathrm{~N}$ molecules under catalytic conditions (vide infra). Consequently, such strategy was not useful to achieve confined catalysis.

In a subsequent synthetic step, amorphous a-3 nanoparticles were converted to micrometre crystalline c-3 particles by heating them at $120{ }^{\circ} \mathrm{C}$ for 7 days in a mixture of dioxane, mesitylene and acetic acid. After exposing the treated solid under vacuum conditions, evacuated c-3 was obtained in the form of microcrystals with dimensions of nearly $1 \mu \mathrm{m}$ in diameter (Figure 3a). PXRD showed the characteristic pattern of COF-300 (Figure 3b). ${ }^{20}$ Moreover, c-3 did not show significant spectroscopic changes in both FT-IR and solid-state ${ }^{13} \mathrm{C}$ MAS NMR spectra in comparison to those seen for a-3 (see S. I. Figures S13 and S7, respectively). TGA analysis for the c-3 did not display any significant weight loss in the range of 50-400 ${ }^{\circ} \mathrm{C}$, confirming the evacuation of guest molecules from its framework (see S. I., Figure S18). This observation was further corroborated by $\mathrm{N}_{2}$ sorption measurements at $77 \mathrm{~K}$. As shown in Figure 3c, evacuated c-3 showed to be porous after mild activation conditions ( 2 hours of primary vacuum at room temperature). The properties of this material matched with the previously reported data: ${ }^{25}$ the adsorption isotherm presented a S-shape (Type V) centred at $0.1 \mathrm{P} / \mathrm{P}_{0}$ and with a plateau at 400 $\mathrm{cm}^{3} \mathrm{~g}^{-1}$.
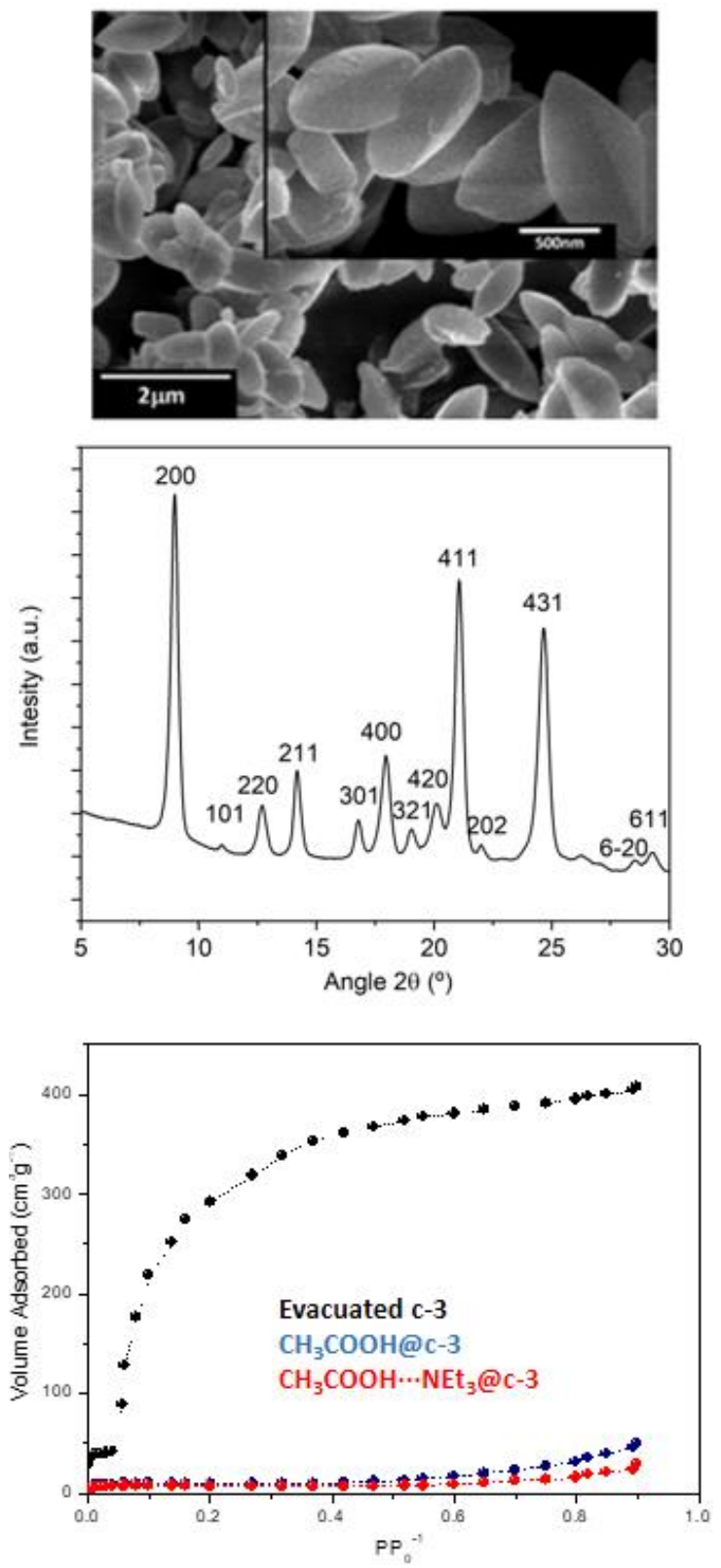

Figure 3 Characterization of c-3 and derivatized materials. a) Representative SEM image of c-3; b) PXRD pattern of c-3; c) Nitrogen adsorption analysis of c-3 (black), crystalline $\mathrm{CH}_{3} \mathrm{COOH} @ \mathrm{c}-3$ (red) and crystalline $\mathrm{CH}_{3} \mathrm{COOH} \cdot$... NEt $\mathrm{NE}_{3} @ \mathrm{c}-3$ (blue). 
Then, evacuated c-3 was functionalized with $\mathrm{CH}_{3} \mathrm{COOH}$ or $\mathrm{CH}_{3} \mathrm{COOH} \cdots \mathrm{NEt}_{3}$ following the same methodology described for the amorphous materials (see S. I., section 1). It should be highlighted that $\mathrm{N}_{2}$ sorption measurements in both $\mathrm{CH}_{3} \mathrm{COOH} @ \mathrm{c}-3$ and $\mathrm{CH}_{3} \mathrm{COOH} \cdot . . \mathrm{NEt}_{3} @ \mathrm{c}-3$ showed a dramatic loss of porosity, with total uptakes decreasing below $50 \mathrm{~cm}^{3} \mathrm{~g}^{-1}$ (49 $\mathrm{cm}^{3} \mathrm{~g}^{-1}$ for $\mathrm{CH}_{3} \mathrm{COOH} @ \mathrm{c}-3$, and $23 \mathrm{~cm}^{3} \mathrm{~g}^{-1}$ for $\mathrm{CH}_{3} \mathrm{COOH}-$ $\left.\mathrm{NEt}_{3} @ \mathbf{c}-3\right)$. Moreover, addition of $\mathrm{CH}_{3} \mathrm{COOH}$ or $\mathrm{CH}_{3} \mathrm{COOH} \cdots \mathrm{NEt}_{3}$ adduct resulted on the change of the isotherms observed to Type III. These changes in the isotherm trend and uptake were indicative of the blocking of the pores by the post-synthetic inclusion of $\mathrm{CH}_{3} \mathrm{COOH}$ and $\mathrm{NEt}_{3}$ molecules.

\section{Catalysis of the materials.}

\section{Comparison of the catalytic activity of amorphous a-3 and crystalline $\mathrm{c}-3$ based materials.}

We started evaluating the catalytic activity of crystalline evacuated c-3 and amorphous evacuated a-3 and the corresponding functionalized materials in two model reactions: the ring-opening epoxide reaction of $\mathbf{4 a}$ with epoxide 5 obtaining product $6 \mathbf{6}$ under acidic conditions and the Knoevenagel reaction between malononitrile 7 and aldehyde 8a, obtaining product 9a under basic conditions. ${ }^{26}$ The results obtained are summarized in Scheme 2 . The evacuated materials a-3 and c-3 showed a negligible catalytic activity for the two processes studied, being observed amounts of product similar to those obtained in control experiments without catalyst. On the contrary, crystalline acidic $\mathrm{CH}_{3} \mathrm{COOH} @ \mathrm{c}-3$ and basic $\mathbf{C H}_{3} \mathbf{C O O H}$...NEt $\mathbf{N}_{3} @ \mathrm{c}-3$ materials showed a moderate catalytic performance for both ring opening epoxide and Knoevenagel reactions, respectively. We attributed this moderate activity to the fact that inclusion of these molecules dramatically reduces the porosity of c-3 (as confirmed by sorption $\mathrm{N}_{2}$ measurements, vide supra), thereby limiting the access of reagents to the internal parts of material. According to this hypothesis, we decided to study the catalytic activity of both amorphous $\mathrm{CH}_{3} \mathrm{COOH} @ a-3$ and $\mathrm{CH}_{3} \mathrm{COOH}$...NEt ${ }_{3} @ a-3$, because they show a much higher external surface area due to their nanosized character. The higher dimension of the particle was $145 \pm 16 \mathrm{~nm}$ for amorphous materials and $1100 \pm 400 \mathrm{~nm}$ for crystalline COFs (see ESI). Indeed, amorphous materials, even though they show lower loadings of active molecules (see S. I. section 6), showed better catalytic performances for both acidic and basic catalytic systems.

We also studied the stability of such materials in the presence of the reactants used in both reactions (see section 12.3 in S.I. for more details). Overall, imine structures are sensitive to the nucleophilic attack that result in erosion of the organic framework as a consequence of the reversible nature of the imine bond. Such decomposition reactivity competes with the catalysed reaction. Consequently, imine structure reactivity limits the output of the catalytic reaction and the recyclability of the corresponding material. a)

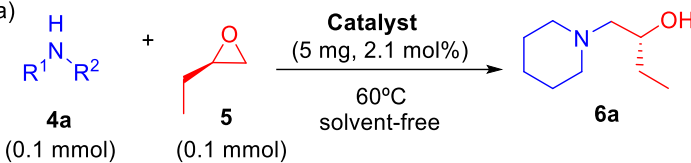

Without catalyst Yield $=\sim 20 \% ; 24 \mathrm{~h}$ c-3 Yield $=\sim 20 \% ; 24 \mathrm{~h}$ a-3 Yield $=\sim 20 \% ; 24 \mathrm{~h}$ $\mathrm{CH}_{3} \mathrm{COOH@c-3} \mathrm{Yield}=45 \% ; 24 \mathrm{~h}$ $\mathrm{CH}_{3} \mathrm{COOH@a-3} \mathrm{Yield} \mathrm{=} \mathrm{73 \% ;} 24 \mathrm{~h}$

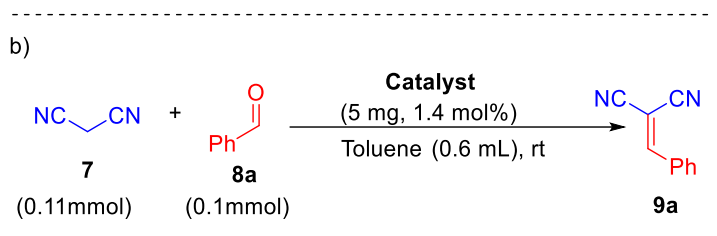

Without catalyst Yield $=<5 \% ; 14 \mathrm{~h}$ c-3 Yield $=<5 \% ; 14 \mathrm{~h}$ a-3 Yield $=<5 \% ; 14 \mathrm{~h}$ $\mathrm{CH}_{3} \mathrm{COOH} \cdots \mathrm{NEt}_{3} @ \mathrm{c}-3$ Yield $=28 \% ; 14 \mathrm{~h}$ $\mathrm{CH}_{3} \mathrm{COOH} \cdots \mathrm{NEt}_{3} @ \mathrm{a}-3$ Yield $=71 \% ; 14 \mathrm{~h}$

Scheme 2 Catalytic activity of the prepared materials for a) ring-opening epoxide reaction and b) Knoevenagel reaction.

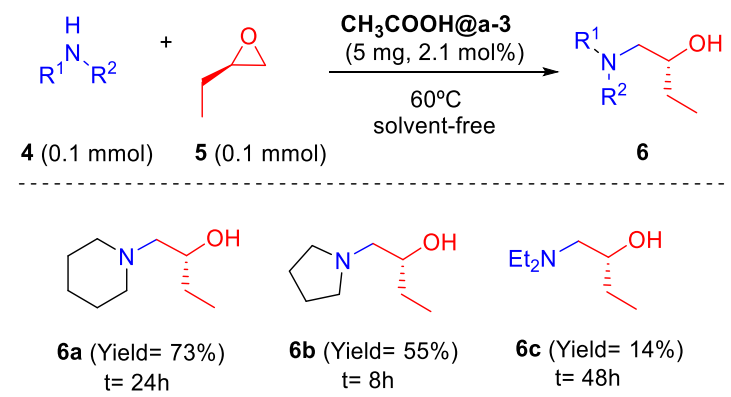

Scheme 3 Scope of epoxide ring opening reactions explored in this work catalysed by $\mathrm{CH}_{3} \mathrm{COOH} @ \mathrm{a}-3$.

Acid catalysis: ring-opening epoxide reaction using $\mathrm{CH}_{3} \mathrm{COOH} @ a-3$. To generalize the use of $\mathrm{CH}_{3} \mathrm{COOH} @ a-3$ to catalyse opening epoxide reactions, we performed different reactions with secondary amines (4b and 4c) following a solvent free procedure. Under these reaction conditions, $\mathrm{CH}_{3} \mathrm{COOH} @ a-3$ catalysed the formation of product $6 \mathbf{b}$ with a $55 \%$ yield (Scheme 3). Moreover, it could also catalysed the formation of $6 \mathrm{c}$ in low yields from $\mathrm{Et}_{2} \mathrm{NH}$ (4c). Accordingly, while we observed a $20 \%$ of conversion that corresponds to the background reaction in the case of $\mathbf{4 a}$ and $\mathbf{4 b}$, the uncatalyzed reaction did not generate a measurable amount of product when $\mathbf{4 c}$ was used as reagent. (see. S. I., section 7).

Basic Catalysis: Knoevenagel Reaction using $\mathrm{CH}_{3} \mathrm{COOH}$...NEt $\mathrm{NE}_{3} @ \mathrm{a}-3$. We next expanded the scope of Knoevenagel reaction using different aldehydes $\mathbf{8 b}$-g (Scheme 4). We found an excellent catalytic outcome, which was maintained with electron donating groups, such as methyl or methoxy groups (9b-c), alkyl groups (9d), and more sterically demanding aldehydes (9e and 9f). However, further increase of the steric hindrance 

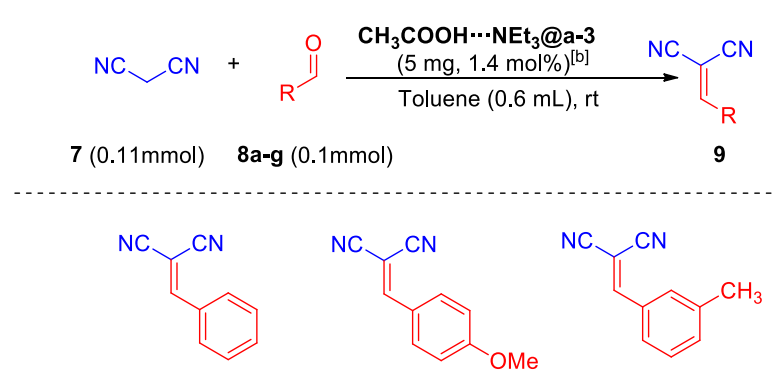

9a, 71\% yield ${ }^{\mathrm{c}}$ 14 hours

9c, $65 \%$ yield 14 hours

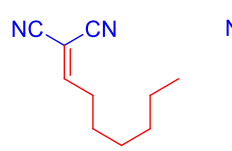

9d, $68 \%$ yield 10 hours

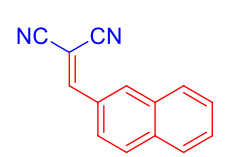

$9 e, 63 \%$ yield 20 hours

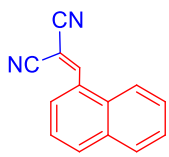

9f, $59 \%$ yield 14 hours

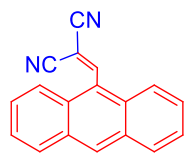

9g, no reaction ${ }^{d}$ 24 hours

Scheme 4 Knoevenagel reactions explored in this work between malononitrile and aldehydes catalysed by $\mathrm{CH}_{3} \mathrm{COOH}$... NEt $\mathrm{NE}_{3} @ \mathrm{a}-3$. [a] All the reactions were performed using $0.11 \mathrm{mmol}$ of acetonitrile $7,0.1 \mathrm{mmol}$ of aldehyde 8 and $5 \mathrm{mg}$ of $\mathrm{CH}_{3} \mathrm{COOH}$-..NEt $\mathrm{NEt}_{3} @ \mathrm{a}-3$ in $0.6 \mathrm{~mL}$ of toluene at room temperature. [b] mol\% obtained from TGA analysis (4.6\% of total mass). [c] A reaction was performed under homogeneous conditions ( $1.4 \mathrm{~mol} \%$ of adduct $\mathrm{CH}_{3} \mathrm{COOH} \cdots \mathrm{NEt}_{3}$ ) in absence of the material, obtaining product $9 \mathrm{a}$ in $77 \%$ yield after $14 \mathrm{~h}$. [d] Full conversion to the product was obtained when free $\mathrm{NEt}_{3}$ was used instead of the porous material.

in reagent $\mathbf{8 g}$ resulted in null conversion to the Knoevenagel product $\mathbf{9 g}$. This result is very interesting considering that product $9 \mathrm{~g}$ could be obtained in homogenous catalysis using $\mathrm{NEt}_{3}$. Therefore, the null reactivity observed using $\mathbf{C H}_{3} \mathbf{C O O H}$...NEt $\mathrm{NE}_{3} @$ a-3 can be understood by a size discrimination effect that seems to point to a catalysis taking place inside the pores of the material. Moreover, the different catalytic activity showed by c-3 and a-3 materials in addition with $\mathrm{N}_{2}$ adsorption experiments of the pre- and postfunctionalized materials, led us to the hypothesis that catalysis using these materials, although confined, should be restricted to pores close to material surface. This hypothesis is also corroborated by DFT calculations (see below). We also discarded the possibility of significant leaching of molecular catalytic species (ie. $\mathrm{CH}_{3} \mathrm{COOH}$ and $\mathrm{NEt}_{3}$ ) from a-3. (see S. I., section 10), except for the case $\mathbf{N E t}_{3} @ \mathbf{a}-\mathbf{3}$ and $\mathbf{N E t}_{3} @ \mathbf{c}-\mathbf{3}$ materials. The weakness of the interaction between the amine molecule $\left(\mathrm{Et}_{3} \mathrm{~N}\right)$ and the porous material, either crystalline or amorphous, resulted in complete leaching of catalytic molecules.

\section{DFT analysis.}

\section{DFT calculations for the imine structure-adsorbed molecules} interactions.

With the aim of further characterizing these materials and supporting the experimental data, DFT calculations with periodic boundary conditions were used to evaluate the

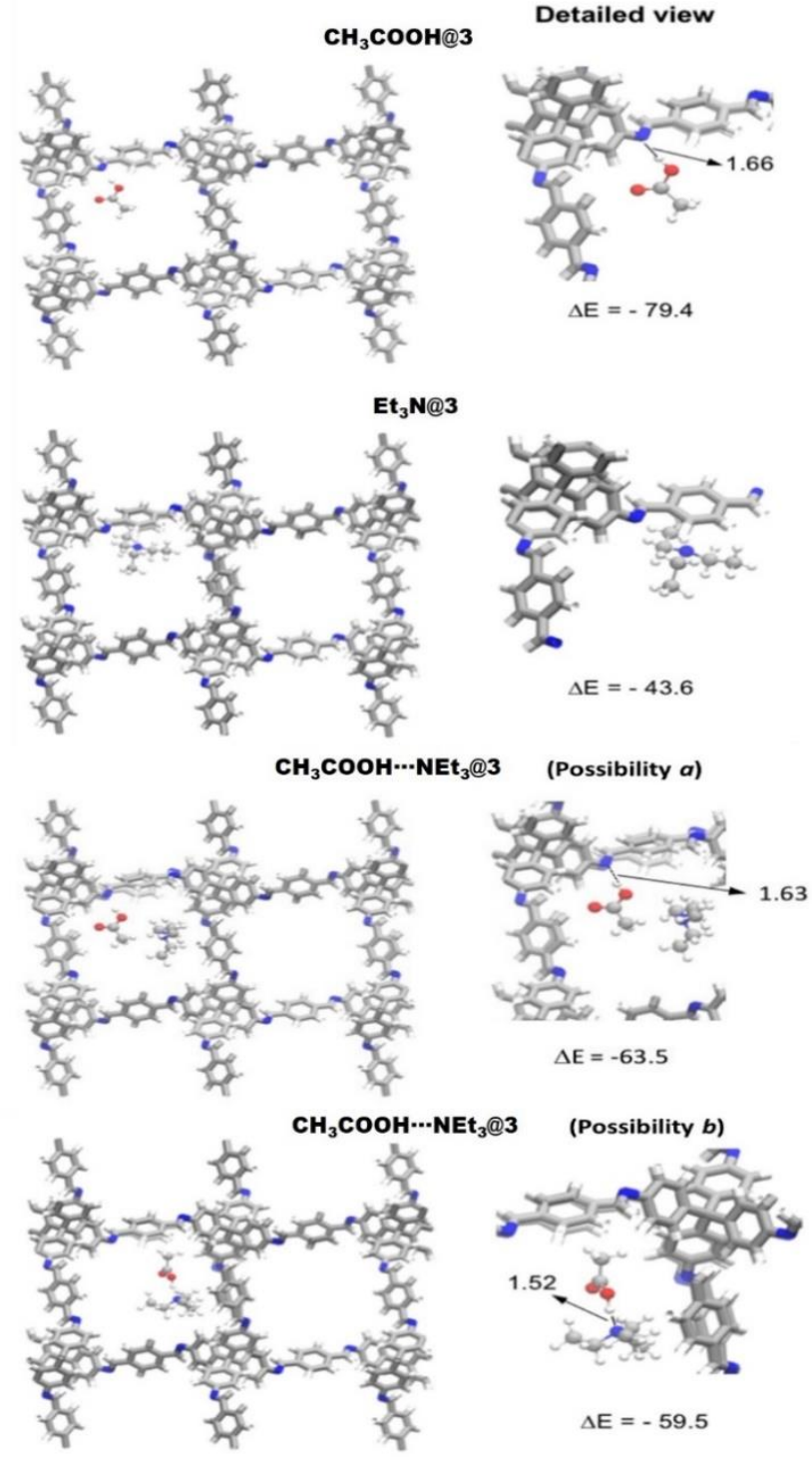

Figure 4 Optimized imine structures where $\mathrm{CH}_{3} \mathrm{COOH}, \mathrm{NEt}_{3}$ and $\mathrm{CH}_{3} \mathrm{COOH} \cdots \mathrm{NEt}$ adducts are included (distances in $\AA$ ), and interaction energies $\left(\mathrm{kJ} \mathrm{mol}^{-1}\right)$ between imine structure and the incorporated molecules.

interaction between the imine structure of $\mathbf{a - 3 / c - 3}$ and $\mathrm{CH}_{3} \mathrm{COOH}, \mathrm{NEt}_{3}$ and $\mathrm{CH}_{3} \mathrm{COOH} \cdots \mathrm{NEt}_{3}$ adduct (see S.I., section 12). Results are presented in Figure 4, showing the optimized geometries, selected geometrical parameters and the adsorption energies of these imine structures functionalized with $\mathrm{CH}_{3} \mathrm{COOH}, \mathrm{NEt}_{3}$ and $\mathrm{CH}_{3} \mathrm{COOH} \cdots \mathrm{NEt}_{3}$ adducts. The interaction between acetic acid and the imine structure is stablished through hydrogen bonding between the acidic proton of the acetic acid and the imine group of the structure (Figure 4, top). The $\mathrm{OH} \cdots \mathrm{N}$ distance is $1.66 \AA$, which is indicative of a strong hydrogen bond. The associated adsorption energy is $-79.4 \mathrm{~kJ} \mathrm{~mol}^{-1}$.

On the other hand, the imine of the structure and the adsorbed amine ( $\mathrm{NEt}_{3}$ ) are both basic and no hydrogen bonding is possible between them. In this context, the adsorption takes place only through Van der Waals interactions and the preferred structure presents the $\mathrm{NEt}_{3}$ close to the walls of the 
imine material. The shortest distances between atoms of $\mathrm{NEt}_{3}$ and those of the imine structure are smaller than $4 \AA$ (Figure 4 , middle). The resulting adsorption energy is $-43.6 \mathrm{~kJ} \mathrm{~mol}^{-1}$.

Finally, we studied the interaction of the $\mathrm{CH}_{3} \mathrm{COOH} \cdots \mathrm{NEt}_{3}$ mixture with the imine structure, considering a 1 to 1 relationship between $\mathrm{CH}_{3} \mathrm{COOH}$ and $\mathrm{NEt}_{3}$ (Figure 4, middle). Within these initial structures, two possibilities almost equally raised as the most favorable situations (see Figure 4 and S. I. Figure S21). The first one can be described as an $\mathrm{CH}_{3} \mathrm{COOH}$ molecule interacting with the imine structure through hydrogen bonding, while the remaining $\mathrm{NEt}_{3}$ molecule interacts with the imine structure and $\mathrm{CH}_{3} \mathrm{COOH}$ through van der Waals interactions. The second one implies the formation of a neutral $\mathrm{CH}_{3} \mathrm{COOH} \cdots \mathrm{NEt}_{3}$ aggregate, interacting with the imine structure through van der Waals interactions. Therefore, the mixture $\mathrm{CH}_{3} \mathrm{COOH}+\mathrm{NEt}_{3}$ in the imine structure shows a combination of intermolecular and molecule-imine structure interactions that enhance the adsorption of the base molecule.

\section{Analysis of Influence of Confinement of the Active Site by DFT Calculations.}

We next explored the Knoevenagel reaction considering two different aldehydes: benzaldehyde (8a) and anthracene-9carbaldehyde (8g) (see S. I. section 12.2 for confinement DFT calculations for the ring-opening epoxide reaction). The reaction of $\mathbf{8 a}$ inside the cavity defined by the imine structure led to the formation of 9 a with a $71 \%$ yield, but $8 \mathrm{~g}$ did not react inside this cavity. Therefore, these two reactions are ideal examples to study the size selectivity.

Considering the homogenous system, molecular calculations in gas phase and solution showed that, regardless the reacting aldehyde, the nucleophilic attack to the carbonyl carbon directly leads to the formation of the alcohol product, resulting from the addition of the deprotonated malononitrile (see S. I.). In solution, the global process is energetically highly favourable (Figure 5, $\Delta \mathrm{E}=-\mathbf{8 2 . 2}$ and $-86.4 \mathrm{~kJ} \mathrm{~mol}^{-1}$ for $\mathbf{8 a}$ and $\mathbf{8 g}$ respectively). The energy barrier with respect to the precomplex are very low in these two cases (less than $26 \mathrm{~kJ} \mathrm{~mol}^{-1}$ ). It is worth mentioning that the main difficulty to perform the reaction is to approach the three reactants (base, malononitrile and aldehyde). However, after thermal corrections, the global activation Gibbs energies are still consistent with a feasible process $\left(\Delta \mathrm{G} \ddagger=96.8\right.$ and $87.6 \mathrm{KJ} \mathrm{mol}^{-1}$ for the $8 \mathrm{a}$ and $8 \mathrm{~g}$ respectively, see Figure 5 and S. I., Figures S23-29). This is consistent with a relatively fast reaction, taking place at room temperature.

Several key features appeared when analysing the reactivity of $\mathbf{8 a}$ and $\mathbf{8 g}$ inside the cavity defined by the imine structure. In particular, aldehyde $\mathbf{8 a}$ is sufficiently small to be accommodated inside the cavity either with the phenyl ring placed along or perpendicular to the channels of the material. This is due to the fact that the width of the phenyl ring is less than half of the cavity section. In contrast, aldehyde $\mathbf{8 g}$ is significantly wider than $\mathbf{8 a}$. Therefore, this imposes that the anthracene aldehyde $\mathbf{8 g}$ can only diffuse in the less hindered

\section{a) Knoevenage/ with $8 a$}

\section{b) Knoevenagel with $8 g$}
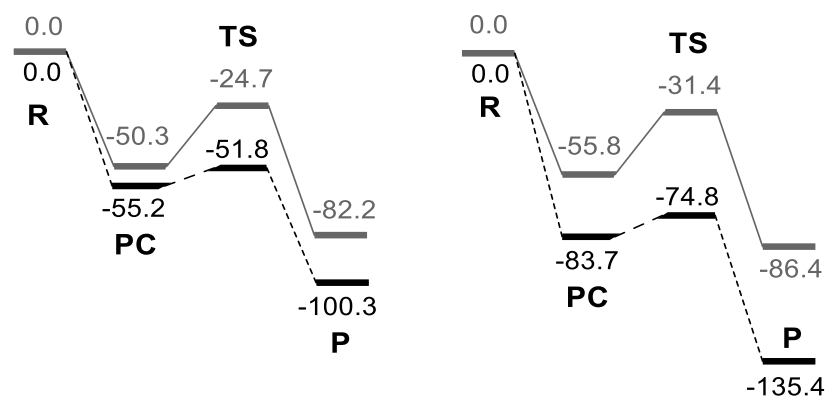

Figure 5. Energy profile in $\mathrm{kJ} \mathrm{mol}^{-1}$ (a) Knoevenagel reaction with $\mathbf{8 a}$ and (b) $\mathbf{8 g}$ Grey curves correspond to the $\mathrm{M06} / 6-311+\mathrm{G}(\mathrm{d}, \mathrm{p})$ values associated with reaction in solution, while values in black correspond to the best estimated values for the reactions inside a cavity defined by the imine structure. $\mathrm{R}$ stands for separated reactants, PC for the reacting precomplex, TS for transition state and P for the products of the elementary step considered.

orientation. Moreover, although several arrangements of the transition state of $\mathbf{8 a}$ without steric hindrance from the cavity could be envisaged, we could only find two possibilities to settle the transition state associated to $\mathbf{8 g}$, but with severe geometrical constrictions (S. I. Figures S23-29). Therefore, diffusion of the reactants and products along the material seems to be much more favourable for $8 \mathrm{a} / \mathbf{9 a}$ than for $\mathbf{8 g} / \mathbf{9 g}$. Overall, although the best estimated energies of the transition states inside the cavity are similar to those in solution, computations suggest that the system involving $\mathbf{8 g}$ has much less flexibility inside the cavity and it would require a very specific orientation, which suggest that this would impose a high entropic penalization. This is especially relevant considering that the model used does not include neither the acetic acid needed to trap the triethylamine nor the solvent. Therefore, the diffusion of the resulting product $\mathbf{9 g}$ would be challenging if ever formed. All this data together suggest that while $\mathbf{8 a}$ and $\mathbf{8 g}$ should react similarly in solution, the reaction of $\mathbf{8 g}$ becomes more difficult inside the cavity. This reinforces the fact that the reaction takes place inside the material and that size selectivity would appear when the reactant is wider than $9-10 \AA$, such is the case of the three fused aromatic rings.

\section{Conclusions}

In this work we successfully carried out the supramolecular functionalization of crystalline $\mathrm{COF}-300$ and related amorphous imine polymer nanoparticles with $\mathrm{CH}_{3} \mathrm{COOH}$ molecules and the adduct $\mathrm{CH}_{3} \mathrm{COOH} \cdots \mathrm{NEt}_{3}$. Gas adsorption experiments on crystalline samples corroborated that functionalization by inclusion of $\mathrm{CH}_{3} \mathrm{COOH}$ molecules or $\mathrm{CH}_{3} \mathrm{COOH} \cdots \mathrm{NEt}_{3}$ adducts occurs inside the pores of material. Considering the accessibility of active centres, we increased the acid/base catalytic activity of these materials by using amorphous imine polymer nanoparticles. Despite that these nanoparticles are amorphous and non-porous, its functionalization with $\mathrm{CH}_{3} \mathrm{COOH}$ molecules and $\mathrm{CH}_{3} \mathrm{COOH} \cdot \cdots \mathrm{NEt}_{3}$ adducts allowed to use them as efficient catalysts for acidic ring opening epoxide and basic Knoevenagel reactions, respectively. Moreover, this catalysis exhibited size 
selectivity in Knoevenagel transformations, suggesting that reactions must take place into cavities of the imine structure located close to the nanoparticle surface. Overall, this work presents a new alternative to modulate the catalytic properties of organic porous materials relying on non-covalent encapsulation of small acidic or basic molecules.

\section{Conflicts of interest}

There are no conflicts to declare.

\section{Acknowledgements}

This work was supported by Spanish Ministerio de Economia y Competitividad (MINECO) (CTQ2017-89132-P; RTI2018095038-B-100) and "Comunidad de Madrid" and European Structural Funds (S2018/NMT-4367). It was also supported by the Generalitat de Catalunya (SGR XSM is grateful for the Professor Agregat Serra Húnter position). R. C. thanks to CAM for the "Atracción de Talento" fellowship.

\section{Notes and references}

1 a) M. Yoshizawa, J. K. Klosterman and M. Fujita, Angew. Chem. Int. Ed., 2009, 48 3418-3438; b) J. M. Wiester, P. A. Ulmann and C. A. Mirkin, Angew. Chem. Int. Ed., 2011, 50, 114-137; c) S. H. A. M. Leenders, R. Gramage-Doria, B. de Bruin and J. N. H. Reek, Chem. Soc. Rev., 2015, 44, 433-448.

2 a) M. Yoshizawa, M. Tamura and M. Fujita, Science, 2006, 312, 251-254; b) A. Cavarzan, A. Scarso, P. Sgarbossa, G. Strukul and J. N. H. Reek, J. Am. Chem. Soc., 2011, 133, 2848-2851; c) R. Gramage-Doria, J. Hessels, S. H. M. Leenders, O. Tröppner, M. Dürr, I. Ivanović-Burmazović and J. N. H. Reek, Angew. Chem. Int. Ed., 2014, 53, 13380-13384.

3 D. M. Dalton, S. R. Ellis, E. M. Nichols, R. A. Mathies, F. D. Toste, R. G. Bergman and K. N. Raymond, J. Am. Chem. Soc., 2015, 137, 10128-10131.

4 a) P. Thordarson, E. J. A. Bijsterveld, A. E. Rowan and R. J. M. Nolte, Nature, 2003, 424, 915-918; b) C. J. Brown, R. G. Bergman and K. N. Raymond, J. Am. Chem. Soc., 2009, 131, 17530-17531; c) C. García-Simón, R. Gramage-Doria, S. Raoufmoghaddam, T. Parella, M. Costas, X. Ribas and J. N. H. Reek, J. Am. Chem. Soc., 2015, 137, 2680-2687.

5 a) J. Chen and J. J. Rebek, Org. Lett., 2002, 4, 327-329; b) P.Howlader, P. Das, E. Zangrando and P. S. Mukherjee, J. Am Chem. Soc., 2016, 138, 138, 1668-1676.

6 See for instance: C. Martínez and A. Corma, Coord. Chem. Rev., 2011, 255, 1558-1580.

7 C. Perego and R. Millini, Chem Soc. Rev., 2013, 42, 3956-3976.

8 A. Kamakar, A. V. Desai and S. K. Ghosh, Chem. Rev., 2016, 307, 313-341.

9 A. P. Coté, A. I. Benin, N. W. Ockwig, M.O'Keeffe, A. J. Matzger and O. M. Yaghi, Science, 2005, 310, 1166-1170.

10 a) M. G. Rabbani, A. K. Sekizkardes, Z. Kahveci, T. E. Reich and R. Ding, Chem. Eur. J., 2013, 19, 3324-3328; b) B. Ashourirad, A. K. Sekizkardes, S. Altarawneh and H. M. El-Kaderi, Chem. Mater., 2015, 27, 1349-1358.

11 a) D. Kaleeswaran, P. Vishnoi and R. Murugavel, J. Mater. Chem. C, 2015, 3, 7159-7171; b) S. Dalapati, S. Jin, J. Gao, Y.
Xu, A. Nagai and D. Jiang, J. Am. Chem. Soc., 2013, 135, 1731017313.

12 a) M. Dogru, M. Handloser, F. Auras, T. Kunz, D. Medina, A. Hartschuh, P. Knochel and T. Bein, Angew. Chem. Int. Ed., 2013, 52, 2920-2924; b) S. Wan, F. Gándara, A. Asano, H. Furukawa, A. Saeki, S. K. Dey, L. Liao, M. W. Ambrogio, Y. Y. Botros, X. Duan, S. Seki, J. F. Stoddart and O. M. Yaghi, Chem. Mater., 2011, 23, 4094-4097.

13 a) L. Stegbauer, K. Schwinghammer and B. V. Lotsch, Chem. Sci., 2014, 5, 2789-2793; b) V. S. Vyas, F. Haase, L. Stegbauer, G. Savasci, F. Podjaski, C. Ochsenfeld and B. V. Lotsch, Nat. Commun., 2015, 6, 8508; c) H. Yang, S. Zhang, L. Han, Z. Zhang and Z. Xue, ACS Appl. Mater. Interfaces, 2016, 8, 5366-5375.

14 a) J. Thote, H. B. Aiyappa, A. Deshpande, D. D. Díaz and S. Kurungot, Chem. Eur. J., 2014, 20, 15961-15965; b) S. Ding, J. Gao, Q. Wang, Y. Zhang, W. Song, C. Su and W. Wang, J. Am. Chem. Soc., 2011, 133, 19816-19822; c) P. Pachfule, S. Kandambeth, D. D. Díaz and R. Banerjee, Chem. Commun., 2014, 50, 3169-3172; d) P. Pachfule, M. Panda, S. Kandambeth, S. M. Shivaprasad and D. Diaz, J. Mater. Chem. A, 2014, 2, 7944-7952.

15 Q. Fang, S. Gu, J. Zheng, Z. Zhuang, S. Qiu and Y. Yan, Angew. Chem. Int. Ed., 2014, 53, $2878-2882$.

16 a) H. Xu, J. Gao and D. Jiang, Nat. Chem., 2015, 7, 905-912; b) H.-L. Qian, C.-X. Yang and X.-P. Yan, Nat. Commun., 2016, 7, 12104.

17 a) X. Han, Q. Xia, J. Huang, Y. Liu, C. Tan and Y. Cui, J. Am. Chem. Soc., 2017, 139, 8693-8697; b) Y. Zhi, P. Shao, X. Feng, H. Xia, Y. Zhang, Z. Shi, Y. Mua and X. Liu, J. Mater. Chem. A, 2018, 6, 374-382.

18 a) V. S. Vyas, M. Vishwakarma, I. Moudrakovski, F. Haase, G. Savasci, C. Ochsenfeld, J. P. Spatz and B. V. Lotsch, Adv. Mater., 2016, 28, 8749-8754; b) S. Royuela, E. García-Garrido, M. Martín Arroyo, M. J. Mancheño, M. M. Ramos, D. González-Rodríguez, A. Somoza, F. Zamora and J. L. Segura, Chem. Commun., 2018, 54, 8729-8732.

19 C. Montoro, D. Rodríguez-San-Miguel, E. Polo, R. EscuderoCid, M. L. Ruiz-Gonzalez, J. A. R. Navarro, P. Ocón and F. Zamora, J. Am. Chem. Soc., 2017, 139, 10079-10086.

20 a) F. J. Uribe-Romo, J. R. Hunt, H.Furukawa, C. Klöck, M.O'Keeffe and O. M. Yaghi, J. Am. Chem. Soc., 2009, 131, 4570-4571. b) According to the diffraction pattern, we can state that our material corresponds to the 7-fold interpenetrated COF-300, which can be expanded depending on the guest molecule. Accordingly, our data points that COF300 exhibits a variable pore size induced during the adsorption processes. Based in our adsorption isotherm data, the adsorbed volume is $40 \mathrm{~cm}^{3} / \mathrm{g}$ around $0.03 \mathrm{P} / \mathrm{P}_{0}$ (before the expansion of the structure where the channel size is $4 \AA$ ). After the step, the adsorbed volume increases until $400 \mathrm{~cm} 3 / \mathrm{g}$ what would correspond to an increase on the pore size (considering an isotropic expansion of the channel size) from $4 \AA$ to $8.6 \AA$ in accordance to referneces 20 c and 20 d. c) T. Ma, J. Li, J. Niu, L. Zhang, A. S. Etman, C. Lin, D. Shi, P. Chen, L.-H. Li, X. Du, J. Sun and W. Wang, J. Am. Chem. Soc., 2018, 140, 6763-6766. d) Y. Chen, Z.-L. Shi,L. Wei, B. Zhou, J. Tan, H.-L. Zhou, Y.-B. Zhang, J. Am. Chem. Soc. 2019, 141, 7, 3298-3303.

21 A. de la Peña-Ruigómez, D. Rodríguez-San-Miguel, K. C. Stylianou, M. Cavallini, D, Gentili, F. Liscio, S. Milita, O. M. Roscioni, M. L. Ruiz-González, C. Carbonell, D. Maspoch, R. Mas-Ballesté, J. L. Segura and F. Zamora, Chem. Eur. J., 2015, 21, 10666-10670.

22 M. C. Daugherty, E, Vitaku, R. L. Li, A. M. Evans, A. M. Evans, A. D. Chavez and W. R. Ditchel, Chem. Commun., 2019, 55, 2680-2683.

23 A. de la Peña-Ruigómez, D. Rodríguez-San-Miguel, K. C. Stylianou, M. Cavallini, D, Gentili, F. Liscio, S. Milita, O. M. Roscioni, M. L. Ruiz-González, C. Carbonell, D. Maspoch, R. 
Mas-Ballesté, J. L. Segura and F. Zamora, Chem. Eur. J., 2015, 21, 10666-10670.

24 In order to verify the hydrogen bonding interaction with other species, we substituted acetic acid by Rhodamine 6G, which also contains an acidic proton in its structure. We synthesized the COF material in the presence of Rhodamine 6G. The resulting COF material contained a $1.8 \%$ in weight of Rhodamine 6G.

25 T. Ma, J. Li, J. Niu, L. Zhang, A. S. Etman, C. Lin, D. Shi, P. Chen, L.-H. Li, X. Du, J. Sun and W. Wang, J. Am. Chem. Soc., 2018, 140, 6763-6766.

26 All the catalytic experiments were performed during a two weeks period from the synthesis of material, because we observed that storage of the materials for longer periods results in the decrease of catalytic activity, probably due to loss $\mathrm{CH}_{3} \mathrm{COOH}$ and/or $\mathrm{NEt}_{3}$ volatile molecules. 
GRAPHICAL ABSTRACT and TEXT (20 words)

Non-covalent inclusion of small acid and base molecules in an imine structure based on COF-300 nanoparticles is presented.

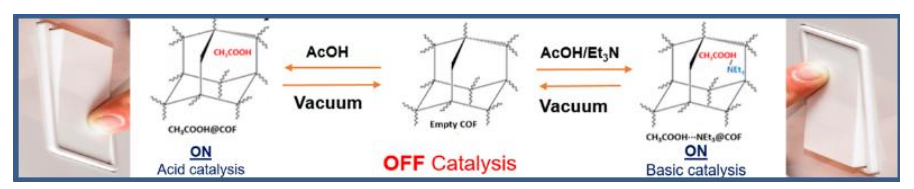

